\title{
Home Quarantine Challenges and Psychological Status of Bangladeshi University Students during COVID-19
}

\author{
${ }^{1}$ BRAC Business School, BRAC University, \\ Dhaka, Bangladesh \\ ${ }^{2}$ Department of Business Administration, \\ Metropolitan University, Sylhet, \\ Bangladesh \\ Correspondence \\ *Corresponding Author. \\ Email: rahman@isu.ac.bd
}

Md. Mizanur Rahman*1 | Md. Saidur Rahaman²

\section{1 | INTRODUCTION}

The existence of the Coronavirus (COVID-19) virus was unfamiliar to the world (Wang, 2020). As the pandemic continues to spread, the virus and its effects to human is noticeable. (Shereen et al., 2020). The first covid variant was discovered in Wuhan China, Province of Hubei (Nishiura, 2020; Cascella et al., 2020; Xiang et al., 2019). Through adapting to the home quarantine strategy, the infected countries including Bangladesh have been combatting against the circumstances. The concept of home quarantine is keeping isolated and detached from people. A COVID-19 patient contact was strongly advised to comply with the 14-day quarantine period. The government of Bangladesh recorded its first COVID-19 case on March 04, 2020. The Institute of Epidemiology, Disease Control, and Research (IEDCR) reported three infected cases on March 07, 2020 (IEDCR, 2020). Due to that event, directives to comply with the home quarantine period were agreed upon by the Government of Bangladesh. As the pandemic continues to strike globally, Bangladesh has recorded a total caseload of 966,406 people infected with the

\section{KEYWORDS:}

Bangladesh, COVID-19, Challenge, Home Quarantine, Psychological Status, Student 
virus (https://bangla.bdnews24.com/). The educational institutions across the country were temporarily closed to prevent the widespread of the virus, students also decided to move to their residence (www.dhakatribune.com). It was new and convenient to stay at home with relatives free from academic stress (Rahaman et al, 2020). The unusual situation and negative ideas appeared. The school reopening and graduation rites were questionable. Alumni and fresh graduates are struggling to find a professional career (Wang et al., 2020).

According to studies, psychological disorders may occur due to the sudden change of lifestyle, anxiety (Dhar et al., 2020), and being uncertain about the future (Aleta et al., 2020). The educational institution's temporary closure and lack of funds may also affect the psychological status of an individual (Rahaman et al, 2020). The United Nations data shows that on the current crisis, seventy-seven (77\%) percent of children in Italy and Spain were inattentive, thirty-nine (39\%) were restless and irritable. Meanwhile, a survey in the United Kingdom stated that thirty-two (32\%) percent of students in the country had suffered mental health weakening (World Health Organization, 2020).

Public health specialists reported that the infected numbers are alarmingly increasing as Bangladeshi people are overlooking the home quarantine period and government guidelines. The World Health Organization's former regional advisor, Professor Muzaherul Huq reported that the people of Bangladesh are unconscious of the pandemic, therefore the government of Bangladesh strictly implemented the home quarantine protocols (New age, 2020). It has become a concern for the general public, including children, adults, professionals and front-line careers, and COVID-19 patients that the pandemic continues to spread across the country (Chen et al., 2020; Yang et al., 2020).

The outbreak appears to worsen the physiological and psychological aspects of an individual (American Psychiatric Association, 2020). Patients who suffer natural cold, fever and shortness of breath were diagnosed with COVID-19. In this situation, researchers stated that the existence of the COVID-19 pandemic has caused panic among people (Bao et al., 2020). Thus, a panic attack causes palpitations, shortness of breath, trembling of limbs, and physical weakness of human beings (Burke et al, 2020). Also, coronavirus endangers psychological conditions, this includes fear of infection (Chen, 2020), death of relatives and family members, uncertainty about livelihood (Xiao, 2020), and financial crisis. In addition, the difficulty in adapting to the quarantine period and notions on the COVID-19 pandemic creates tremendous stress on the mind (Tsai, 2019).

The country and its community are responsible for giving much attention to psychological matters. Otherwise, it will cause social and economic damage to society for a long time to come. However, it is noticeable that researchers and academes are unconscious about the issue. (Rahaman et al, 2020).

The researchers concluded based on the findings of the study that there is no existing study undertaking the psychological status of university students in Bangladesh. Thus, the researchers aims to determine the Home Quarantine (HQ) Challenges and Psychological Status (PS) of Bangladeshi University Students during COVID-19, show the relationship between Home Quarantine (HQ) Challenges and Psychological Status (PS), and measure the impact of HQ challenges on PS of Bangladeshi university students during COVID-19.

In this study, the researchers addressed the conflicts encountered by the students at Bangladeshi University. Also, this study discussed the home quarantine challenges and student's psychological status. The researchers also identified the research gap and set three objectives.

\section{2 | METHODOLOGY}

\section{1 | Study design and subjects' selection}

In this study, the researchers used the snowball sampling technique to distribute the questionnaire. Google Form was used by the researchers for the questionnaire. The researchers also used various social media platforms to send the form. The questionnaire was forwarded to a group of people to collect data. The target respondent of the study was two hundred fifty (250) students from Dhaka and Sylhet division, aged eighteen (18) and above. A total of two hundred sixty-nine (269) students responded to the research questionnaire. The researchers selected two hundred fifty (250) (92.93\%) respondents as a sample.

\section{2 | Pattern of the questionnaire and pilot study}

The researchers categorized the questionnaire into three dimensions. Five (5) questions based on the demographic information were included. The respondents were required to answer under the first category. The question includes a) do you have any idea about home quarantine?" If yes, you are requested to fill out the next section. Under the second category, five (5) questions 
based on the challenges experienced by the respondents during the home quarantine period were asked. Also, another five (5) questions were asked based on the respondents' psychological status. The data were collected through the 5 Likert Type Scale, excluding the demographic information. Upon collecting responses from thirty (30) students, the researcher conducted a pilot study to check the reliability of the studied variables. The pilot study shows the reliability value of home quarantine-related items (.735) and psychological status-related items (.755) this shows a good consistency of data.

\section{3 | Participants}

In this study, the researchers used demographic statistics to identify the respondent's demographic characteristics: a) gender; b) age; c) level of education; and d) marital status. The following Table 1 presents the demographical statistics of the respondents.

TABLE 1 Demographic Information of the Respondents

\begin{tabular}{|c|c|c|}
\hline Respondents' Characteristics & Frequency & Percentage \\
\hline \multicolumn{3}{|l|}{ Gender } \\
\hline Male & 178 & 71.20 \\
\hline Female & 72 & 28.80 \\
\hline \multicolumn{3}{|l|}{ Age (Years) } \\
\hline $18-30$ & 187 & 74.80 \\
\hline $31-40$ & 38 & 15.20 \\
\hline 41-above & 25 & 10.00 \\
\hline \multicolumn{3}{|l|}{ Marital Status } \\
\hline Married & 68 & 27.20 \\
\hline Unmarried & 182 & 78.80 \\
\hline \multicolumn{3}{|l|}{ Level of Education } \\
\hline Bachelor & 136 & 54.40 \\
\hline Masters & 68 & 27.20 \\
\hline Others & 46 & 18.40 \\
\hline
\end{tabular}

Source: Online survey, 2020

As can be seen from the data, $70.85 \%$ of the respondents are male, and $29.15 \%$ are female, $27.15 \%$ are married respondents and $72.85 \%$ are unmarried. $74.28 \%$ of the students are between the ages of 18 and 30 . It can be gleaned from the data that $54.28 \%$ of the students have a Bachelor's degree.

\section{4 | Measures}

\subsection{1 | Psychological status}

The researchers selected five (5) items based on the study of Brooks et al, (2020) considering the Bangladeshi university students. In addition, 5 Likert Type Scale: $1=$ Strongly Disagree, $5=$ Strongly Agree were adopted in this study. Table 2 shows the item selection with relevant literature and reliability value.

\subsection{2 | Home Quarantine Challenges}

The researchers used the home quarantine challenges as an independent variable and five (5) items were used from a study (Brooks et al. 2020). Table 2 shows the item selection with relevant literature and with reliability value. 


\section{5 | Ethical consideration}

The director of Metropolitan University Sylhet, Bangladesh's Center for Teaching, Research, and Publication (CTRP) submitted the ethical letter to the university registrar and approved the conduct of research.

\section{3 | ANALYSES AND FINDINGS}

In analyzing this study, the researchers used preliminary and inferential analyses. The accuracy of the data, reliability, normality, and multicollinearity, was analyzed. Demographic analysis was carried out to identify the demographic information of the respondents. The researchers used percentile calculation, correlation, and multiple regression analysis under the inferential section.

\section{1 | Preliminary analyses}

\subsection{1 | Reliability analyses}

The researchers conducted a reliability analysis to find the consistency of the set data used in the study. Table 2 reliability value on the conducted pilot study (30 respondents) and the reliability value on the actual set data (250 respondents).

TABLE 2 Reliability values

\begin{tabular}{|c|c|c|c|c|}
\hline & \multirow{2}{*}{ List of the Items } & \multirow{2}{*}{ Sources } & \multicolumn{2}{|c|}{ Reliability } \\
\hline & & & Pilot study & Actual \\
\hline $\begin{array}{l}\text { Psychological } \\
\text { status dur- } \\
\text { ing Home } \\
\text { Quarantine } \\
\text { (PS) }\end{array}$ & $\begin{array}{l}\text { Fear of infection } \\
\text { I am perpetually downcast and anxious. } \\
\text { I cannot concentrate my regular activities. } \\
\text { My routine distracts my attention. } \\
\text { I'm fed up and bored. }\end{array}$ & $\begin{array}{l}\text { Brooks, S. K., Webster, } \\
\text { R. K., Smith, L. E., } \\
\text { Woodland, L., Wessely, } \\
\text { S., Greenberg, N., \& } \\
\text { Rubin, G. J. (2020) }\end{array}$ & .755 & .824 \\
\hline $\begin{array}{l}\text { Challenges } \\
\text { of Home } \\
\text { Quarantine } \\
(\mathrm{CH})\end{array}$ & $\begin{array}{l}\text { Insufficient financial support from family } \\
\text { Not getting proper support from the government } \\
\text { We are not aware about HQ } \\
\text { Insufficient medical support } \\
\text { Inadequate information about HQ }\end{array}$ & $\begin{array}{l}\text { Brooks, S. K., Webster, } \\
\text { R. K., Smith, L. E., } \\
\text { Woodland, L., Wessely, } \\
\text { S., Greenberg, N., \& } \\
\text { Rubin, G. J. (2020). }\end{array}$ & .735 & .821 \\
\hline
\end{tabular}

*Missing data, normality, outliers and multicollinearity

The researchers analyzed the missing information on the datasheet and found eleven (11) respondents failed to answer the questionnaire completely. The Skewness and Kurtosis values for home quarantine and psychological status is less than (+- 3), which indicates that the data was normally distributed. The researchers also used Malhanobis and Cook's distance to identify either the data is free from outliers or not, thus, as seen on the data eight (8) responses fell in outlier boundary. To identify the multicollinearity problem, Variance Inflation Factor (VIF) and tolerance values were also used, result finds no multicollinearity problem. The VIF value and tolerance are presented in the regression table. The researchers deleted nine-teen (19) responses $(11+8=19)$ due to missing information and outliers. The rest of the analyses were done based on the two hundred fifty (250) responses $(269-19=250)$ 


\subsection{Inferential analyses}

Based on the percentile values (see Table 3, the most significant challenges of home quarantine for Bangladeshi University students are lack of awareness of its advantages (82\%), insufficient financial support from family (78\%), and unsatisfactory medical support (77\%). However, in psychological status, $73.6 \%$ of students fear infection. In addition, $71 \%$ of students are distracted by their regular activities, and $70 \%$ of students experienced boredom and fed up during the home quarantine period in Bangladesh.

TABLE 3 Respondents' opinion (percentage)

\begin{tabular}{llccccccc}
\hline & List of the Items & $\mathbf{1}$ & $\mathbf{2}$ & $\mathbf{3}$ & $\mathbf{4}$ & $\mathbf{5}$ & $\mathbf{4 + 5}$ & Rank \\
\hline Psychological & Fear of infection & 4.5 & 7.9 & 14 & 45 & 28.6 & 73.6 & 1 \\
status dur- & I am perpetually downcast and anxious. & 5.0 & 10.3 & 15.8 & 47.0 & 21.9 & 68.9 & 4 \\
ing Home & I cannot concentrate my regular activities. & 6.5 & 7.5 & 15 & 41.5 & 29.5 & 71 & 2 \\
Quarantine & My routine distracts my attention. & 12.5 & 15.9 & 14.4 & 30 & 27.6 & 57.2 & 5 \\
(PS) & I'm fed up and bored. & 2.0 & 11.4 & 16.3 & 49.0 & 21.3 & 70.3 & 3 \\
\hline \multirow{2}{*}{ Challenges } & Insufficient financial support from family & 5.0 & 5.0 & 12 & 49 & 29 & 78 & 3 \\
of Home & Not getting proper support from the government & 7.0 & 8.0 & 10 & 48 & 27 & 75 & 4 \\
Quarantine & People are not aware about HQ & 8.0 & 2.5 & 7.5 & 32 & 50.0 & 82 & 1 \\
(CH) & Insufficient medical support & 7.0 & 8 & 8.0 & 50 & 27 & 77 & 2 \\
& Inadequate information about HQ & 3.0 & 7.4 & 21.3 & 40.1 & 30.2 & 70.3 & 5 \\
\hline
\end{tabular}

1 - Strongly Disagree $(\%)$

2 - Disagree $(\%)$

3 - Neutral (\%)

4 - Agree (\%)

5 - Strongly agree $(\%)$

$4+5$ - Total Agreement $(\%)$

\subsection{1 | Correlations}

TABLE 4 Correlation values

\begin{tabular}{llcc}
\hline & & Psychological status & HQ challenges \\
\hline Psychological status & Pearson Correlation & 1 & .112 \\
HQ challenges & Pearson Correlation & $.364 * *$ & 1 \\
\hline
\end{tabular}

**Correlation is significant at the 0.01 level (2-tailed).

The Table 4 above shows the home quarantine challenge is positively $(r=.364 * *)$ related to the psychological status of the students on the COVID-19 pandemic period and the value is significant.

\subsection{2 | Multiple Regression}

The pattern of relationship between home quarantine challenges and psychological status, as well as its effect, was studied using an Ordinary Least Square (OLS) multiple regression model shown in Table 5 
The overall regression model is significant ( $F=1.74, P=.00$ ), and the independent variable (HQ challenges) accounting for 38.1 percent of variance for the dependent variable (psychological status). Adj. $R^{2}$ is close to $R^{2}$, indicating that adding more independent variables has a slight effect on prediction ability. Further, home quarantine challenges positively affect ( $\beta=$ $.287, p=00)$ the psychological status of the Bangladeshi students during the COVID-19 pandemic outbreak. It represents the increase in home quarantine challenges, the level of psychological statuses such as stress, fear, stigma, depression, and frustration.

TABLE 5 OLS Regression analysis

\begin{tabular}{|c|c|c|c|c|c|c|c|c|}
\hline \multicolumn{9}{|c|}{ Coefficients } \\
\hline \multirow[b]{2}{*}{ Model } & & \multicolumn{2}{|c|}{ Unstandardized Coefficients } & \multicolumn{2}{|c|}{ Standardized Coefficients } & \multicolumn{3}{|c|}{ Collinearity Statistics } \\
\hline & & B & Std. Error & Beta & $\mathbf{t}$ & Sig. & Tolerance & VIF \\
\hline \multirow[t]{2}{*}{1} & (Constant) & 2.670 & .461 & & 5.79 & .000 & & \\
\hline & HQ challenges & .287 & .132 & .121 & 1.957 & .000 & .945 & 1.065 \\
\hline \multicolumn{9}{|c|}{ Dependent Variable: Psychological status } \\
\hline Model & & $R$ & $R^{2}$ & Adjusted $R^{2}$ & SEE & DW & $\mathbf{F}$ & Sig. \\
\hline 1 & & $.381^{a}$ & .292 & .261 & .937 & 1.68 & 1.74 & $.000^{b}$ \\
\hline
\end{tabular}

SEE - Standard Error of Estimate

DW - Durbin-Watson

\section{4 | DISCUSSION OF THE FINDINGS}

The aim of this study, therefore, is to find the effect of home quarantine, its challenges, and the psychological status of university students in Bangladesh. Based on the findings of this study, the researchers only identified the perception of home quarantine challenges. In addition, this study also focused on the current situation of the Bangladeshi University students as well as their psychological status.

The findings of this study show that among the total number of respondents, eighty-two (82\%) of the students were unaware of the home quarantine advantages. Likewise, the findings support the report of Professor Muzaherul Huq, ex-advisor of the World Health Organisation (New age, 2020). According to Professor Huq, the people of Bangladesh is unconscious and not complying with the quarantine guidelines. In a nutshell, based on the data lack of financial support from the parents (78\%) and lack of medical support (77\%) were also included in the challenges of the home quarantine period of the respondents. However, akin to the percentage there are students who shared their opinion concerning the inadequate medical support from the government. These opinions supported the published reports of the renowned newspaper in Bangladesh (New age, 2020). According to the research findings and published report, most of the COVID-19 tests are situated in the capital city where generally, people lacked proper medical support (New age, 2020). The respondents also stated that Bangladesh is a populated country and its government lacked the capacity to provide the basic support for its citizens.

It is noteworthy to mention, too, that based on the psychological status of the respondents, $73.6 \%$ of students fear the infection, $71 \%$ of students are distracted with their regular activities, and $70.3 \%$ of students experience boredom and stress. Further, the findings of this study are comparable to the study undertaken by Mamun et al (2021), this study stated that 33.3\% of the citizens in Bangladesh are suffering from depression in the COVID-19 pandemic. Meanwhile, a study conducted by Banna et al, (2020) shows that $59.7 \%$ of its citizen are severely stressed. As reflected on the data, the researchers gathered a high percentage of responses on the "fear and stigma" experienced by the Bangladeshi University students.

As shown in the data, there is a positive correlation between quarantine challenges and $(\beta=.287, p<0.00)$ on the COVID19 pandemic. This represents the increase in quarantine challenges, the level of stress, fear, stigma, depression, and frustration. As the findings of the study are unique, it was difficult to point out the consistency with other results. Moreover, a positive relationship between home quarantine challenges and psychological status was also observed. Meanwhile, it was also shown in 
the data that the cases of home quarantine challenges, including the stress, fear, stigma, depression, and frustration experienced by the students were decreasing. The study also proposed suggestions based on the findings of the entire research.

\subsection{Strengths and contributions of this research}

According to the research data (4th April 2020), there is no existing study ventured on the home quarantine challenge and psychological status of university students in Bangladesh. The study will support the officials and authorities including the Health Ministry, IEDCR, Education Ministry, universities, educational institutions, and the government of Bangladesh. Based on the research recommendations the Bangladeshi government may use this study to overcome challenges and cope psychologically in times of pandemic.

\section{5 | CONCLUSION AND RECOMMENDATIONS FOR POLICY MAKING}

As home quarantine protocol in COVID- 19 pandemic shall be complied, psychological conditions might worsen. The distraction on daily routines brought by the pandemic, the boredom experienced in isolating, frustrations, and distress may also affect the psychological status of an individual (Das et al 2021). It is important to note that in this study, $71 \%$ agreed that it has been difficult to keep concentrated. In the quarantine period, technology plays an important role in communicating. (Rahaman et al 2020). Further, the regression model shows that extending the home quarantine period worsens stress, fear, stigma, depression, and frustration. Thus, the researchers suggested the following recommendations:

1. Having less knowledge regarding the home quarantine is one of the crucial challenges for the respondents. Therefore, the government is highly recommended to suggest flexible quarantine rules and regulations promote awareness. A short film may be produced and played presenting the positive outcome of complying with the home quarantine period.

2. Lack of health support is also a challenge during the home quarantine period. The health care units may (Ministry of Heath) may identify the issue for the public and raise awareness. Moreover, the government of Bangladesh may provide incentives for doctors, nurses, and front-line workers to bring motivation.

3. In times of pandemic keeping in touch with family members, relatives and friends is an effective strategy to stay psychologically sound (free from stress, fear, stigma, and frustration). In-home quarantine period using gadgets (mobile phones, charger, laptops, adaptor, goggles, pillow, etc.) is also suggested to avoid anxiety attacks, stress, and frustration. The government of Malaysia has been offering 1 Gigabyte of data for one SIM Card user. The government of Bangladesh may collaborate with telecommunication companies to execute this strategy.

\section{1 | Limitations and areas for future research}

Only two divisions (Dhaka and Sylhet) in Bangladesh were selected for analysis, making it extremely difficult to obtain valuable results. It is strongly recommended to gather more respondents around the country for the study. This study overlooked the relationship between demographic variables, home quarantine, and psychological status. As a result, it has been decided to proposed future studies that would focus on the relationship between demographic variables, challenges of the home quarantine period, and psychological status. Also, only quantitative data analysis was used in this study. Further, future studies are recommended to use qualitative data analysis and various methods for a significant result.

\section{References}

Aleta, A., Martín-Corral, D., y Piontti, A. P., Ajelli, M., Litvinova, M., Chinazzi, M., .. Moreno, Y. (2020, August). Modelling 
the impact of testing, contact tracing and household quarantine on second waves of COVID-19. Nature Human Behaviour, 4(9), 964-971. Retrieved from https://doi.org/10.1038/s41562-020-0931-9 doi: 10.1038/s41562-020-0931-9

Bangladesh closes all educational institutions till March 31. (2020, March). Retrieved 2021-09-02, from https:// www.dhakatribune.com/bangladesh/dhaka/2020/03/16/govt-directs-shutting-all-educational -institutions-mach-17-to-31

Banna, M. H. A., Sayeed, A., Kundu, S., Christopher, E., Hasan, M. T., Begum, M. R., ... Khan, M. S. I. (2020, August). The impact of the COVID-19 pandemic on the mental health of the adult population in bangladesh: a nationwide crosssectional study. International Journal of Environmental Health Research, 1-12. Retrieved from https://doi.org/ 10.1080/09603123.2020.1802409 doi: 10.1080/09603123.2020.1802409

Bao, C., Liu, X., Zhang, H., Li, Y., \& Liu, J. (2020, June). Coronavirus disease 2019 (COVID-19) CT findings: A systematic review and meta-analysis. Journal of the American College of Radiology, 17(6), 701-709. Retrieved from https:// doi.org/10.1016/j.jacr.2020.03.006 doi: 10.1016/j.jacr.2020.03.006

Brooks, S. K., Webster, R. K., Smith, L. E., Woodland, L., Wessely, S., Greenberg, N., \& Rubin, G. J. (2020, March). The psychological impact of quarantine and how to reduce it: rapid review of the evidence. The Lancet, 395(10227), 912-920. Retrieved from https://doi.org/10.1016/s0140-6736(20)30460-8 doi: 10.1016/s0140-6736(20)30460-8

Burke, R. M., Killerby, M. E., Newton, S., Ashworth, C. E., Berns, A. L., Brennan, S., ... and (2020, July). Symptom profiles of a convenience sample of patients with COVID-19 - united states, january-april 2020. MMWR. Morbidity and Mortality Weekly Report, 69(28), 904-908. Retrieved from https://doi.org/10.15585/mmwr.mm6928a2 doi: 10.15585/mmwr.mm6928a2

Cascella, M., Mauro, I., Blasio, E. D., Crispo, A., Gaudio, A. D., Bimonte, S., ... Ascierto, P. A. (2020, July). Rapid and impressive response to a combined treatment with single-dose tocilizumab and NIV in a patient with COVID-19 pneumonia/ARDS. Medicina, 56(8), 377. Retrieved from https://doi.org/10.3390/medicina56080377 doi: 10.3390/medicina56080377

Chang, K.-C., Strong, C., Pakpour, A. H., Griffiths, M. D., \& Lin, C.-Y. (2020, December). Factors related to preventive COVID19 infection behaviors among people with mental illness. Journal of the Formosan Medical Association, 119(12), 17721780. Retrieved 2021-09-02, from/https://linkinghub.elsevier.com/retrieve/pii/S0929664620303442 doi: 10.1016/j.jfma.2020.07.032

Chen, L. Y., Hong, J., \& Bloomberg. (2020). Coronavirus hits China's workers as businesses say they can't pay wages now. Retrieved 2021-09-02, from https://fortune.com/2020/02/19/coronavirus-china-workers -businesses-pay-wages/

Chen, Q., Liang, M., Li, Y., Guo, J., Fei, D., Wang, L., ... Zhang, Z. (2020, April). Mental health care for medical staff in China during the COVID-19 outbreak. The Lancet Psychiatry, 7(4), e15-e16. Retrieved 2021-09-02, from https:// linkinghub.elsevier.com/retrieve/pii/S221503662030078X doi: 10.1016/S2215-0366(20)30078-X

Das, R., Hasan, M. R., Daria, S., \& Islam, M. R. (2021). Impact of covid-19 pandemic on mental health among general bangladeshi population: a cross-sectional study. BMJ Open, 11(4). Retrieved from https://bmjopen.bmj .com/ content/11/4/e045727 doi: 10.1136/bmjopen-2020-045727

Desclaux, A., Badji, D., Ndione, A. G., \& Sow, K. (2017, April). Accepted monitoring or endured quarantine? Ebola contacts' perceptions in Senegal. Social Science \& Medicine, 178, 38-45. Retrieved 2021-09-02, from https://linkinghub .elsevier.com/retrieve/pii/S0277953617300898 doi: 10.1016/j.socscimed.2017.02.009

Dhar, B. K., Ayittey, F. K., \& Sarkar, S. M. (2020). Impact of COVID-19 on Psychology among the University Students. Global Challenges, 4(11), 2000038. Retrieved 2021-09-02, from https://onlinelibrary ·wiley . com/doi/abs/10.1002/ gch2.202000038 doi: $10.1002 / \mathrm{gch} 2.202000038$

ECDC. (2020). Resource estimation for contact tracing, quarantine and monitoring activities for COVID-19 cases in the EU/EEA (Tech. Rep.). Retrieved from https://www.ecdc.europa.eu/sites/default/files/documents/COVID -19-resources-for-contact-tracing-2-March-2020.pdf

Institute of Epidemiology Disease Control (IEDCR). (2020). Research and corona info. Retrieved from corona.gov.bd publisher: Institute of Epidemiology Disease Control (IEDCR).

Mamun, M. A., Sakib, N., Gozal, D., Bhuiyan, A. I., Hossain, S., Bodrud-Doza, M., ... Pakpour, A. H. (2021, January). The COVID-19 pandemic and serious psychological consequences in Bangladesh: A population-based nationwide study. Journal of Affective Disorders, 279, 462-472. Retrieved 2021-09-02, from https://linkinghub.elsevier.com/ retrieve/pii/S0165032720328809 doi: 10.1016/j.jad.2020.10.036 
New Age Bangladesh. (2020). Experts sceptical of proper home quarantine in Bangladesh. Retrieved 2021-0902, from https://www.newagebd.net/article/102357/experts-sceptical-of-proper-home-quarantine -in-bangladesh publisher: New Age Bangladesh.

Nishiura, H., Kobayashi, T., Miyama, T., Suzuki, A., Jung, S.-m., Hayashi, K., .. Linton, N. M. (2020, May). Estimation of the asymptomatic ratio of novel coronavirus infections (COVID-19). International Journal of Infectious Diseases, 94, 154-155. Retrieved 2021-09-02, from https://linkinghub.elsevier.com/retrieve/pii/S1201971220301399 doi: 10.1016/j.ijid.2020.03.020

Rahaman, M. S., Rahman, M. M., \& Moral, I. H. (2020). Informative knowledge and challenges of home quarantine during COVID-19 in bangladesh. International Journal of Technology Transfer and Commercialisation, 17(4), 354. Retrieved from https://doi.org/10.1504/ijttc.2020.113212 doi: 10.1504/ijttc.2020.113212

Sandbu, M. (2020, March). Coronavirus: the moment for helicopter money. Financial Times. Retrieved 2021-09-02, from https://www.ft.com/content/abd6bbd0-6a9f-11ea-800d-da70cff6e4d3

Shereen, M. A., Khan, S., Kazmi, A., Bashir, N., \& Siddique, R. (2020, July). COVID-19 infection: Emergence, transmission, and characteristics of human coronaviruses. Journal of Advanced Research, 24, 91-98. Retrieved from https://doi . org/10.1016/j.jare.2020.03.005 doi: 10.1016/j.jare.2020.03.005

Tsai, J., \& Wilson, M. (2020, April). COVID-19: a potential public health problem for homeless populations. The Lancet Public Health, 5(4), e186-e187. Retrieved from https : //doi .org/10.1016/s2468-2667 (20) 30053-0 doi: 10.1016/s24682667(20)30053-0

Wang, L.-Y., Cui, J.-J., Ouyang, Q.-Y., Zhan, Y., Guo, C.-X., \& Yin, J.-Y. (2020, October). Remdesivir and COVID-19. The Lancet, 396(10256), 953-954. Retrieved from https://doi.org/10.1016/s0140-6736(20)32019-5 doi: 10.1016/s0140-6736(20)32019-5

Xiang, X., Qian, K., Zhang, Z., Lin, F., Xie, Y., Liu, Y., \& Yang, Z. (2020, September). CRISPR-cas systems based molecular diagnostic tool for infectious diseases and emerging 2019 novel coronavirus (COVID-19) pneumonia. Journal of Drug Targeting, 28(7-8), 727-731. Retrieved 2021-09-02, from https://www.tandfonline.com/doi/full/10.1080/ 1061186X.2020.1769637 doi: 10.1080/1061186X.2020.1769637

Yang, K.-C., Torres-Lugo, C., \& Menczer, F. (2020, June). Prevalence of Low-Credibility Information on Twitter During the COVID-19 Outbreak. arXiv:2004.14484 [cs]. Retrieved 2021-09-02, from http://arxiv.org/abs/2004.14484 arXiv: 2004.14484. doi: 10.36190/2020.16

How to cite this article: M. Rahman, S. Rahaman, (2021), Home Quarantine Challenges and Psychological Status of Bangladeshi University Students during COVID-19, Journal of Education, Management and Development Studies, Vol. 1 No. 2.

This work is licensed under a Creative Commons Attribution-NonCommercial-NoDerivatives 4.0 International License 